\title{
Card displacement response as affected by brainstem lesions in the rat
}

\author{
ROBERT THOMPSON \\ Louisiana State University, Baton Rouge, Louisiana 70803
}

Rats previously trained to push aside a stimulus card in order to gain access to an area of safety showed a marked impairment of the habit following lesions to either the corpus striatum, anterior thalamus, ventromedial thalamus, lateral hypothalamus, subthalamus, prerubral area, substantia nigra, ventral tegmental area, cerebral peduncle, or pontine reticular formation. Lesions to other brainstem areas had no deleterious effects on the card displacement habit.

In the preceding studly (Thompson, 1976a), card displacement performance was examined in the presence of lesions to the neocortex, cerebellum, and limbic forebrain areas. The current paper reports the outcome of discrete lesions to the brainstem on the execution of this response. As in the earlier paper, data are also presented on the integrity of shock-escape behavior.

\section{METHOD}

Adult male albino rats of the Wistar strain were used. Under the motive of escape from footshock. all rats were initially trained to displace a card in order to gain access to the goalbox and were subsequently trained on one or more visual discrimination problems. Following learning, these animals were subjected to bilateral electrolytic lesions to different parts of the brainstem. The size of the lesions, which varied from one brainstem area to another. was comparable to that illustrated in an earlier paper (Thompson, 1974) that also canvassed many different brainstem areas with lesions. Following a 2- to 4-week recovery period, all animals were tested for retention. As described earlier (Thompson. 1976a), notations of behavior on the first 2 days of the retention test served as a basis for ranking each animal on a 3-point scale for card displacement performance (CDP) and escape response performance (ERP).

\section{RESULTS}

Table 1 presents the percentage of subjects from each group that exhibited a disturbance (having a score above 1) in CDP and ERP. (The sham operated controls were the same as those reported in the related paper.)

In Figure 1, those areas critical for CDP are shown in cross-hatching on the left side of each section. These areas are composites of lesion placements in those rats having a score of 3 on CDP and coming from groups that differed significantly from the controls in CDP. The right side of each section shows those areas (stipples) critical for ERP. These areas

This research was supported in part by a grant from the Graduate Council on Research, Louisiana State University.
Table 1

Percentage of Rats Showing a Disturbance in Card Displacement Performance (CDP) and Escape Response Performance (ERP)

\begin{tabular}{|c|c|c|c|}
\hline Group & $\mathrm{N}$ & CDP & ERP \\
\hline Control (sham operated) & 15 & 0 & 6.7 \\
\hline Nucleus accumbens septi & 7 & $42.9 *$ & 28.6 \\
\hline Caudoputamen & 8 & $75.0^{*}$ & 37.5 \\
\hline Globus pallidus & 9 & $100 *$ & $67.7^{*}$ \\
\hline Entopeduncular area & 11 & $100 *$ & $45.5 *$ \\
\hline \multicolumn{4}{|l|}{ Hypothalamus } \\
\hline Anteromedial & 5 & 0 & 0 \\
\hline Anterolateral & 10 & 10.0 & 0 \\
\hline Posteromedial & 14 & 14.3 & 21.4 \\
\hline Posterolateral & 12 & $83.3^{*}$ & $83.3^{*}$ \\
\hline Mamillary bodies & 6 & 33.3 & 16.7 \\
\hline \multicolumn{4}{|l|}{ Thalamus } \\
\hline Anterior & 11 & $45.5^{*}$ & 27.3 \\
\hline Lateral & 9 & 11.1 & 11.1 \\
\hline Dorsomedial & 9 & 0 & 11.1 \\
\hline Ventromedial & 13 & $53.8 *$ & $46.2 *$ \\
\hline Ventral & 13 & 15.4 & 30.8 \\
\hline Nucleus posterior & 12 & 8.3 & $50.0^{*}$ \\
\hline Nucleus parafascicularis & 10 & 0 & $90.0^{*}$ \\
\hline Lateral geniculate & 4 & 0 & 0 \\
\hline Medial geniculate & 10 & 0 & 0 \\
\hline Subthalamic nucleus & 8 & $75.0^{*}$ & $87.5^{*}$ \\
\hline Zona incerta & 8 & 25.0 & 37.5 \\
\hline Pretectal area & 7 & 0 & 0 \\
\hline \multicolumn{4}{|l|}{ Midbrain reticular formation } \\
\hline Rostral & 16 & 6.3 & 12.5 \\
\hline Prerubral & 13 & $30.8^{*}$ & $30.8^{*}$ \\
\hline Suprarubral & 5 & 0 & 0 \\
\hline Supranigral & 7 & 0 & 14.3 \\
\hline Basolateral & 19 & 5.3 & 0 \\
\hline Caudal & 12 & 16.7 & 16.7 \\
\hline \multicolumn{4}{|l|}{ Other midbrain areas } \\
\hline Superior colliculus & 11 & 0 & 0 \\
\hline Inferior colliculus & 9 & 0 & 11.1 \\
\hline Subcollicular area & 8 & 0 & 0 \\
\hline Central gray & 14 & 0 & 7.1 \\
\hline Ventral tegmental area & 9 & $67.7^{*}$ & $55.6 *$ \\
\hline Substantia nigra & 15 & $33.3^{*}$ & 13.3 \\
\hline Cerebral peduncle & 14 & $50.0^{*}$ & 7.1 \\
\hline Red nucleus & 14 & 7.1 & 21.4 \\
\hline Rostral central tegmentum & 12 & 8.3 & $50.0^{*}$ \\
\hline Caudal central tegmentum & 14 & 0 & 14.3 \\
\hline Lateral lemniscal area & 17 & 11.8 & 5.9 \\
\hline Pontine reticular formation & 15 & $26.7 *$ & 13.3 \\
\hline
\end{tabular}

${ }^{*} p<.05$ (Fisher exact probability' test). 


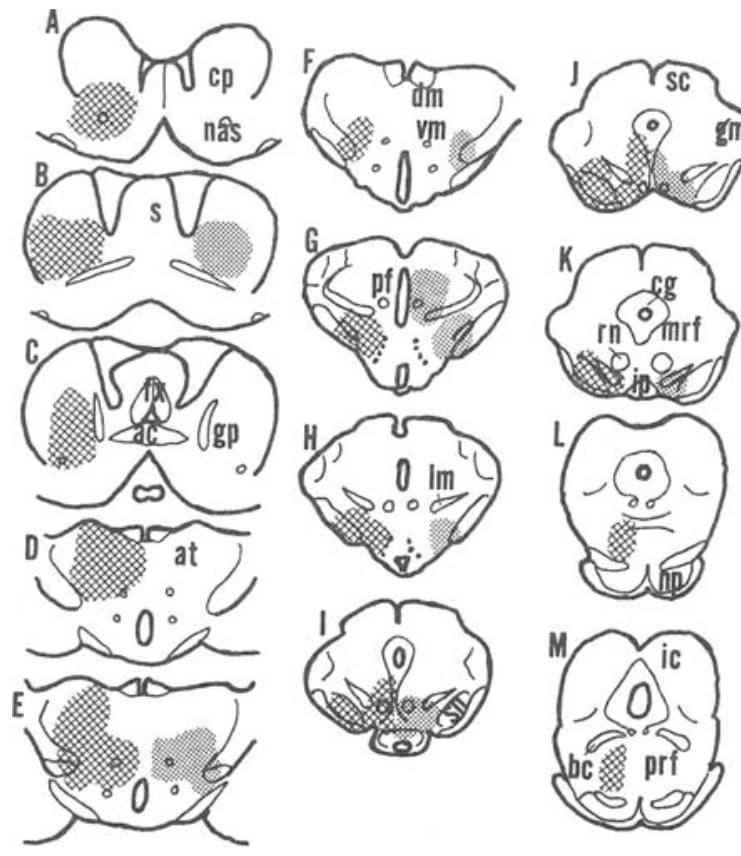

Figure 1. Critical areas for card displacement performance [cross-hatched] and escape response performance [stipples] shown at 13 frontal levels of the brainstem of the rat. [Abbreviations: ac $=$ anterior commissure, at $=$ anterior thalamus, bc $=$ brachium conjunctivum, $\mathbf{c g}=$ central gray, $\mathbf{c p}=$ caudoputamen, $\mathbf{d m}=$ dorsomedial thalamus, $f x=$ fornix column, $g m=$ medial geniculate, $\mathrm{gp}=$ globus pallidus, ic $=$ inferior colliculus, ip $=$ interpeduncular nucleus, $I m=$ medial lemniscus, mrf $=$ midbrain reticular formation, nas = nucleus accumbens septi, np $=$ nucleus pontis, pf $=$ nucleus parafasoicularis, prf $=$ pontine reticular formation, $m=$ red nucleus, $\mathrm{s}=$ septal area, $\mathrm{sc}=$ superior colliculus, $\mathrm{sn}=$ substantia nigra, $\mathrm{vm}=$ ventromedial thalamus.]

are likewise composites of lesion placements, but are derived from those rats having a score of 3 on ERP and coming from groups that differed significantly from the controls in ERP. For convenience, all areas critical for CDP will be termed the CDP system (CDPS) and all areas critical for ERP will be termed the ERP system (ERPS).

It will be observed that those structures composing the CDPS roughly correspond to those composing the ERPS, but areas of no overlap do exist.

\section{DISCUSSION}

The results of the current study coupled with those of the preceding study (Thompson, 1976a) suggest that CDP in the rat is dependent upon the integrity of the parieto-fronto-cingulate region of the cerebrum and a more or less continuous "pathway" extending from the nucleus accumbens septi, through the corpus striatum, thalamus, hypothalamus, and subthalamus, to the ventral portions of the midbrain and pontine reticular formation. It is probably more than coincidence that the subcortical division of the CDPS occupies structures which parallel the trajectory of many of the descending fiber systems having their origin within the parieto-fronto-cingulate cortex (Domesick, 1969; Knook, 1965; Leonard, 1969).

The fact that the CDPS and the ERPS overlap at many different sites within the brain would suggest that a motivational deficit might be responsible, at least in part, for the disturbance in CDP. Yet, the results of the related study and those of the current study have shown that the CDP deficit may arise independent of any loss in ERP, and vice versa. Perhaps the groups that are most illustrative of this dissociative effect are the ones with lesions of the cerebral peduncle and the nucleus parafascicularis. In the former group, 7 of the 14 rats showed a CDP loss, but only 1 showed an ERP loss. In the latter group, 9 of the 10 rats exhibited a disturbance in ERP, but none exhibited a disturbance in CDP.

Granting the fact that a motivational involvement may not altogether account for the CDP loss, then the possibility of some subtle sensorimotor disorder must be seriously considered. Since CDP is probably not dependent upon nor guided by visual, auditory, vestibular, or olfactory cues, it may have a kinesthetic basis very much like the maze habit (Thompson, 1974). Support for this possibility comes from the finding that virtually every area composing the CDPS has been demonstrated to be essential for the performance of a maze habit (Thompson, 1974) and a vestibulo-kinesthetic discrimination habit (Thompson, 1976b). Could it be that the structures involved in this correspondence function in CDP by virtue of their relevance to the construction and/or utilization of a "cognitive map" which must be intact in order to carry out purposive movements culminating in the pushing aside of a barrier? Further studies are needed to answer this important question. ${ }^{1}$

\section{NOTE}

1. Since rats with lesions of the anterior cingulate cortex, a component of the CDPS, have not been reported to exhibit a retention deficit of a leverpressing response (Rosenkilde \& Divac. 1975). it must be assumed that the brain mechanisms underlying CDP are somewhat different from those underlying manipulative acts.

\section{REFERENCES}

Domesick, V. B. Projections from the cingulate cortex in the rat. Brain Research, 1969, 12, 296-320.

KNOOK, $\mathrm{H}$. L. The fiber-connections of the forebrain. Philadelphia: F. A. Davis. 1965.

LEONARD, C. M. The prefrontal cortex of the rat: I. Cortical projections of the mediodorsal nucleus. II. Efferent connections. Brain Research, 1969, 12, 321-343.

Rosenkilde, C. E., \& Divac, I. DRL performance following anteromedial cortical ablations in rats. Brain Research, $1975,95,142-146$.

Thомpson, R. Localization of the "maze memory system" in the white rat. Physiological Psychology, 1974, 2, 1-17.

Thompson, R. Card displacement response as affected by neocortical, cerebellar, and limbic forebrain lesions in the rat. Bulletin of the Psychonomic Society, 1976, 8. 101-102. (a)

Thompson, R. Stereotaxic mapping of brainstem areas critical for memory of visual discrimination habits in the rat. Physiological Psychology, 1976, 4, 1-10. (b)

(Received for publication April 12, 1976.) 